\title{
Structure of a Calcium-dependent 11R-Lipoxygenase Suggests a Mechanism for $\mathrm{Ca}^{2+}$ Regulation ${ }^{*[5}$
}

Received for publication, January 16, 2012, and in revised form, May 7, 2012 Published, JBC Papers in Press, May 9, 2012, DOI 10.1074/jbc.M112.343285

Priit Eek ${ }^{\ddagger}$, Reet Järving ${ }^{\ddagger}$, Ivar Järving ${ }^{\ddagger}$, Nathaniel C. Gilbert ${ }^{\S}$, Marcia E. Newcomer ${ }^{\S}$, and Nigulas Samel ${ }^{\ddagger 1}$

From the ${ }^{\ddagger}$ Department of Chemistry, Tallinn University of Technology, Akadeemia tee 15, 12618 Tallinn, Estonia and the

${ }^{\S}$ Department of Biological Sciences, Louisiana State University, Baton Rouge, Lousiana 70803

Background: Lipoxygenases vary in their catalytic specificity and regulation.

Results: $11 R$-LOX, strictly $\mathrm{Ca}^{2+}$-dependent, displays novel structural features in the membrane-binding domain.

Conclusion: A model for how access to an enclosed active site is linked to $\mathrm{Ca}^{2+}$-dependent membrane binding is proposed.

Significance: The 11R-LOX model provides structural insights into the allosteric regulation of lipoxygenases.

Lipoxygenases (LOXs) are a key part of several signaling pathways that lead to inflammation and cancer. Yet, the mechanisms of substrate binding and allosteric regulation by the various LOX isoforms remain speculative. Here we report the $2.47-\AA$ resolution crystal structure of the arachidonate $11 R$-LOX from Gersemia fruticosa, which sheds new light on the mechanism of LOX catalysis. Our crystallographic and mutational studies suggest that the aliphatic tail of the fatty acid is bound in a hydrophobic pocket with two potential entrances. We speculate that LOXs share a common T-shaped substrate channel architecture that gives rise to the varying positional specificities. A general allosteric mechanism is proposed for transmitting the activityinducing effect of calcium binding from the membrane-targeting PLAT (polycystin-1/lipoxygenase/ $\alpha$-toxin) domain to the active site via a conserved $\pi$-cation bridge.

Lipoxygenases $(\mathrm{LOXs})^{2}$ are non-heme iron dioxygenases that catalyze the stereo- and regiospecific hydroperoxidation of polyunsaturated fatty acids (1). LOX catalysis products of arachidonic acid (AA), which is the main substrate in animals, are hydroperoxyeicosatetraenoic acids (HpETEs), these lipid mediators and their metabolites have been implicated in cancer (2), atherosclerosis (3), and allergic inflammation (4). Consequently, LOXs are targets for drug design. A complicating factor in the development of LOX inhibitors is that there are several LOX isoforms in an organism, all with equivalent catalytic machinery and chemical mechanism (5). Thus, differences in regiospecificity or regulation must be exploited to design iso-

* This work was supported by National Science Foundation Grant MCB 0818387 (to M. E. N.), Estonian Science Foundation Grants 8276 (to I. J.) and 9410 (to N. S.), the Estonian Ministry of Education and Research Grant SF140010s08 (to N. S.), and the European Union Seventh Framework Programme Project VFP414 (to Prof. Mihkel Kaljurand and Dr. Mihkel Koel).

5 This article contains supplemental Figs. S1-S4.

The atomic coordinates and structure factors (code 3vf1) have been deposited in the Protein Data Bank, Research Collaboratory for Structural Bioinformatics, Rutgers University, New Brunswick, NJ (http://www.rcsb.org/).

${ }^{1}$ To whom correspondence should be addressed. Tel.: 372-620-4376; Fax: 372-620-2828; E-mail: nigulas.samel@ttu.ee.

${ }^{2}$ The abbreviations used are: LOX, lipoxygenase; PLAT, polycystin-1/lipoxygenase/ $\alpha$-toxin; AA, arachidonic acid; HpETE, hydroperoxyeicosatetraenoic acid; HETE, hydroxyeicosatetraenoic acid; bis-Tris, 2-[bis(2hydroxyethyl)amino]-2-(hydroxymethyl)propane-1,3-diol. form-specific inhibitors. Given the limited amount of structural information of arachidonate-metabolizing LOXs, each new structure provides crucial details related to LOX catalysis mechanism.

LOX catalysis begins with a stereoselective hydrogen abstraction by the catalytic non-heme iron from the methylene carbon $\left(\mathrm{CH}_{2}\right)$ of the selected 1,4-cis,cis-pentadiene unit on the fatty acid substrate, and is followed by regioselective dioxygen addition on the opposite face of the substrate either at -2 or +2 carbon (Fig. 1) (6). For such specific reactions to take place, a very distinct substrate channel that goes past the non-heme iron must position the fatty acid. This binding site must also vary among LOX isoforms to facilitate the different catalytic properties. The substrate-binding cavity has been described as "boot-shaped"; it is directly accessible from the surface of the protein and ends with a hydrophobic pocket (7). The pocket residues of several 12/15-LOXs have been mutated to demonstrate that bulkier side chains favor 15-lipoxygenation, whereas less space-filling residues, which would allow the fatty acid tail to penetrate deeper into the cavity, confer 12-LOX activity. These results are consistent with aliphatic tail-first entry $(8-12)$. Also, a cationic arginine near the entrance of the cavity has been shown to stabilize the carboxylate head of the fatty acid (13). Computational docking studies based on x-ray crystallography data further support the boot-shaped substrate channel $(14,15)$. For some LOXs, carboxylate head-first binding has been suggested to explain differing specificity or double dioxygenation of AA $(16,17)$. In the light of the coral $8 R$-LOX crystal structure, however, a novel binding model was proposed with an alternative U-shaped channel that neglects the hydrophobic pocket (18). According to this hypothesis, the substrate is bound in a culvert that runs under a conserved arched helix; distinct lipoxygenases allow access to the catalytic iron from one of two possible directions. Although several lipoxygenase crystal structure models have been published, including rabbit $12 / 15$-LOX $(19,20)$, coral $8 R$-LOX $(18,21)$, and recently a modified human 5-LOX (22) representing Animalia, the lack of experimental evidence on substrate binding, such as a crystallized enzyme-substrate complex, has precluded the emergence of a uniform theory.

The activity of various LOXs depends more or less on the presence of $\mathrm{Ca}^{2+}$ that promotes interactions with the lipid 


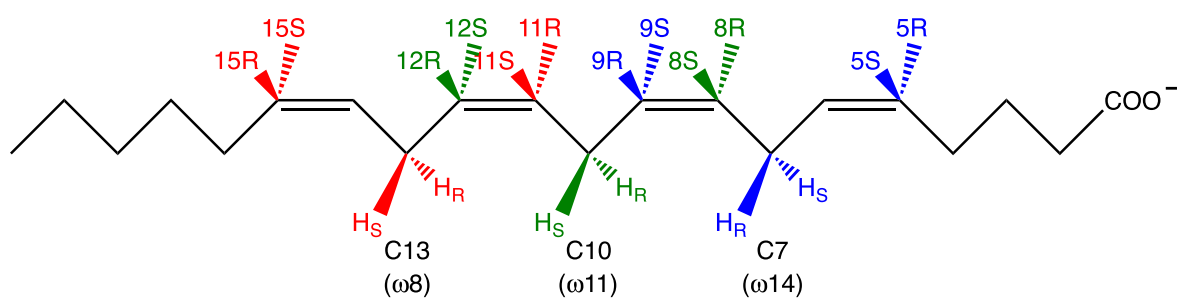

FIGURE 1. All 12 possible lipoxygenation positions in AA. The catalysis begins with stereoselective hydrogen abstraction from C7, C10, or C13 (labeled $\operatorname{proS} / R$ ), followed by antarafacial dioxygen addition either at -2 or +2 carbon (grouped by colors). Based on data from Ref. 6 .

membrane, from where the enzyme obtains its fatty acid substrate $(21,23)$. The human 5 - $\mathrm{LOX}$ is effectively translocated to the nuclear envelope upon $\mathrm{Ca}^{2+}$ release, the C2-like PLAT domain being the selective membrane-targeting module (24). The calcium-binding sites of the PLAT domain appear to be conserved among human 5-LOX, coral 8R-LOX, gangrene $\alpha$-toxin, as well as coral $11 R$-LOX, which are all induced by $\mathrm{Ca}^{2+}$, but not in rabbit $12 / 15$-LOX, which is only mildly affected $(21,25)$. The molecular mechanism of $\mathrm{Ca}^{2+}$ - and membrane-induced allosteric regulation is not clear. Although many mammalian lipoxygenases retain their reaction specificity after PLAT domain truncation, this is accompanied by reduced turnover rates (26). Moreover, tight association of PLAT and catalytic domains has been shown to be important for protein stability and catalytic activity (27). A possible structural element that may be under allosteric control is the $\alpha 2$ region that forms a "lid" over the putative substrate channel entrance, which can adopt different conformations, thereby either opening or closing the orifice $(20,28,29)$. Another plausible allosteric mechanism could involve oligomerization, which has been noticed in case of human platelet 12-LOX and rabbit $12 / 15$-LOX $(30,31)$, but no definite assembly has been described to date.

The arachidonate $11 R$-LOX from the white sea coral Gersemia fruticosa is the first described lipoxygenase with $11 R$ specificity (25). Based on primary structure comparison it is most closely related to the $8 R$-LOX from the allene oxide synthase-lipoxygenase fusion protein of the Caribbean sea whip coral Plexaura homomalla (42\% identity) (32) and the analogous enzyme from G. fruticosa (43\%) (33). The closest mammalian counterparts are 5-LOXs (about 33\%). Experiments with alternative substrates suggest that the fatty acid enters the active site tail-first, as the catalysis specificity depends on the distance of the bisallylic methylene from the methyl end of the aliphatic tail (25). The conserved Gly/Ala sequence determinant, which acts like a switch that directs oxygen to either -2 or +2 carbon ( $R$ - or $S$-stereospecificity, respectively) (34), has been identified as $\mathrm{Gly}^{416}(25)$, which agrees with previous findings linking glycine to $R$-stereoconfiguration. An important feature of the $11 R$-LOX is its complete dependence on both $\mathrm{Ca}^{2+}$ and lipid membranes, the presence of both components is necessary for catalytic activity (25). This, together with the remarkable stability and relative similarity of the enzyme to human 5-LOX, makes it an exceptional subject to study the mechanism of lipoxygenase catalysis specificity and regulation.

Hereby we report the 2.47 - $\AA$ crystal structure model of the coral $11 R$-LOX that suggests a potential allosteric mechanism involving the PLAT domain and the $\alpha 2$ lid region. A highly conserved $\pi$-cation bridge was found that could mediate the regulatory effect of the PLAT domain to the active site. Additionally, a mutation analysis of the hydrophobic pocket in the boot-shaped cavity was conducted to address questions regarding substrate binding. A general hypothesis of possible substrate orientations in the active site is described.

\section{EXPERIMENTAL PROCEDURES}

Expression and Purification-Recombinant G. fruticosa $11 R$ LOX with an $\mathrm{N}$-terminal $\mathrm{His}_{4}$ tag in pET-11a vector was transformed into Escherichia coli BL21(DE3) cells (Novagen). Colonies were grown overnight in $25 \mathrm{ml}$ of LB containing $100 \mu \mathrm{g} / \mathrm{ml}$ of ampicillin at $37^{\circ} \mathrm{C}$. A $500-\mathrm{ml}$ volume of autoinducing medium ZYM-5052 (35) (with $100 \mu \mathrm{g} / \mathrm{ml}$ ampicillin) was inoculated with $5 \mathrm{ml}$ of overnight culture. The culture was incubated at $37^{\circ} \mathrm{C}$ for $3-4 \mathrm{~h}$, followed by growth to saturation at $20^{\circ} \mathrm{C}$. Cells were harvested by centrifugation and frozen at $-80^{\circ} \mathrm{C}$ when the absorbance at $600 \mathrm{~nm}$ had remained stable for $4 \mathrm{~h}$ (usually $27-30 \mathrm{~h}$ after the inoculation).

Cell pellets were resuspended in Bugbuster (Novagen) with added DNase I, pepstatin, and PMSF. The suspension was stirred and incubated on ice for $30 \mathrm{~min}$, lysed in a French pressure cell, and centrifuged at $39,000 \times g$ for $40 \mathrm{~min}$ at $4{ }^{\circ} \mathrm{C}$. The supernatant was applied onto a HisTrap Ni-Sepharose column (GE Healthcare) and washed with binding buffer (50 mM Tris$\mathrm{HCl}, 500 \mathrm{~mm} \mathrm{NaCl}, 20 \mathrm{~mm}$ imidazole, $\mathrm{pH}$ 8.0) on an ÄKTA FPLC system (GE Healthcare). The protein was eluted with an imidazole gradient from 20 to $200 \mathrm{~mm}$. Protein fractions were dialyzed overnight against $20 \mathrm{~mm}$ Tris- $\mathrm{HCl}, \mathrm{pH}$ 8.0, or desalted in a Sephadex G-25 Fine column (Amersham Biosciences). The sample was then applied onto a Mono $Q$ anion exchanger (GE Healthcare), washed with $20 \mathrm{~mm}$ Tris- $\mathrm{HCl}, \mathrm{pH}$ 8.0, and eluted with a $\mathrm{NaCl}$ gradient from 0 to $500 \mathrm{~mm}$. Concentrated protein fractions were run on a Superdex 200 size exclusion column (GE Healthcare) with $20 \mathrm{~mm}$ Tris- $\mathrm{HCl}, \mathrm{pH} 8.0$, and $150 \mathrm{~mm}$ $\mathrm{NaCl}$. For long term storage, the protein was concentrated to $\sim 15 \mathrm{mg} / \mathrm{ml}$, flash frozen in liquid nitrogen, and stored at $-80^{\circ} \mathrm{C}$.

Protein Crystallization-Showers of plate-like crystals formed in 1-2-day-old hanging-drop vapor diffusion experiments that contained a 1:1 mixture of $5 \mathrm{mg} / \mathrm{ml}$ of protein solution and reservoir solution $(0.1 \mathrm{~m}$ bis-Tris, $\mathrm{pH} 7.2,11-12 \%$ (w/v) PEG 3350, $15 \%(w / v)$ sucrose) at $22^{\circ} \mathrm{C}$. To obtain fewer and bigger crystals a microseed stock was prepared using the Seed Bead (Hampton Research) in stabilizing solution with 0.1 M bis-Tris, pH 7.2, 9\% (w/v) PEG 3350, and 15\% (w/v) sucrose. Seeding experiments were conducted with drops containing 2:1:1 mixture of protein and reservoir solution as described 


\section{Regulation of 11R-Lipoxygenase Catalysis}

above and serial dilutions of seed stock as described in the Seed Bead user guide. Larger single crystals grew in 2-3 days. For cryoprotection, crystals were transferred into $0.1 \mathrm{M}$ bis-Tris, $\mathrm{pH}$ $7.2,12 \%(\mathrm{w} / \mathrm{v})$ PEG 3350, 20-25\% (w/v) sucrose in two consecutive steps and then frozen in liquid nitrogen or a $100 \mathrm{~K}$ cryostream.

Data Collection and Structure Determination-Preliminary screens for crystal diffraction were conducted at the Gulf Coast Protein Crystallography Consortium beamline at the Center for Advanced Microstructures and Devices (CAMD, Louisiana State University). A full dataset was collected at the NE-CAT beamline 24-ID-E at the Advanced Photon Source (Argonne, IL) using 0.98 - $\AA$ radiation at $100 \mathrm{~K}$. Data were processed to a resolution of $2.47 \AA$ (Table 1) using xia2 (36). The structure was determined by molecular replacement with $\operatorname{MrBUMP}(37,38)$ using 3.2- $\AA$ P. homomalla $8 R$-LOX model (PDB code 2 fnq). The initial refinement cycles were performed with REFMAC5 (39). Both MrBUMP and REFMAC5 are part of the CCP4 suite (40). Manual model building was done with COOT (41) and further refinement in PHENIX (42) using the program phenix.refine with non-crystallographic symmetry and Ramachandran restraints, individual isotropic atomic displacement factors, and automatic water picking. For the final refinement, hydrogens were added to the model, Ramachandran restraints were released and both stereochemistry and atomic displacement weights were optimized. Illustrations were prepared with UCSF Chimera (43), surfaces were obtained with MS-MS (44). The dimerization interface was analyzed using PISA (Protein Interfaces, Surfaces and Assemblies) (European Bioinformatics Institute) (45). Sequences were aligned with ClustalW2 (46) and rendered with ESPript (47).

Site-directed Mutagenesis-The V430A, L431A, V609A, and V609W mutations were introduced using whole plasmid PCR primed with complementary primers that additionally contained silent mutations for restriction analysis. The M606A mutant was obtained by separately cloning the upstream and downstream fragments of the recombinant cDNA using mutation-containing primers with respective cDNA upstream or downstream primers. Purified fragments were merged using PCR and the cDNA was ligated back into $\mathrm{pET}-11$ a vector (Stratagene) into the BamHI site. The desired mutations were confirmed by sequencing. For whole plasmid PCR protocol, the following DNA primers were used with their complementary primers for mutagenesis: $5^{\prime}$-GGT GCG GCT GAC AAA GCG CTG AGC ATT GGT GGA GG-3' for V430A, 5' -GGT GCG GCT GAC AAG GTG GCT AGC ATT GGT GGA GG-3' for L431A, 5' -GTT ACA ATG GTT TCA GCT GTG AAT GCG C-3' for V609A, $5^{\prime}$-ACA ATG GTT TCT TGG GTT AAC GCG CTA ACC ACG A-3' for V609W, and the following primers for cloning fragments with M606A mutation: $5^{\prime}$-AA GGA TCC ATG CAT CAC CAT CAC ATG AAG TAC AAG-3' (11RLOX cDNA upstream) and 5'-G CGC ATT CAC AAC AGA AAC AGC TGT AAC AGC TTG-3' (M606A downstream) for the upstream fragment, $5^{\prime}$-CAA GCT GTT ACA GCT GTT TCT GTT GTG AAT GCG C-3' (M606A upstream) and 5'-GAT GGA TCC TTA GAT GGC AAT ACT GTT CGG-3' (11R-LOX cDNA downstream) for the downstream fragment.
Enzyme Assay-Initial enzyme specificity experiments were conducted on crude bacterial lysates. BL21-CodonPlus(DE3)RP cells (Stratagene) were transformed and grown in LB medium with $100 \mu \mathrm{g} / \mathrm{ml}$ of ampicillin at $37^{\circ} \mathrm{C}$. Following 500 $\mu \mathrm{M}$ isopropyl $\beta$-D-thiogalactoside induction at $A_{600 \mathrm{~nm}}=0.6$, cells were grown for $16-18 \mathrm{~h}$ at $10^{\circ} \mathrm{C}$. Cells were harvested by centrifugation at $4{ }^{\circ} \mathrm{C}$, washed with $50 \mathrm{~mm}$ Tris- $\mathrm{HCl}, \mathrm{pH}$ 8.0, aliquoted, and frozen at $-80^{\circ} \mathrm{C}$.

For product analysis, aliquots of $2.5 \mathrm{ml}$ of culture were resuspended in $500 \mu \mathrm{l}$ of $50 \mathrm{~mm}$ Tris- $\mathrm{HCl}, \mathrm{pH}$ 8.0, with $1 \mathrm{~mm}$ PMSF and sonicated $3 \times 5 \mathrm{~s}$ using a Torbéo 36810 -Series cell disruptor (Cole Parmer) at a setting of 5 . The suspension was centrifuged at $13,000 \times g$ for $20 \mathrm{~min}$ at $4{ }^{\circ} \mathrm{C}$ and the supernatant was harvested. $\mathrm{CaCl}_{2}$ was added to the enzyme solution in final concentration of $10 \mathrm{~mm}$. Incubations of 1-20 ml were carried out in $50 \mathrm{~mm}$ Tris- $\mathrm{HCl}, 250 \mathrm{~mm} \mathrm{NaCl}, \mathrm{pH} 9.0$ buffer with $50 \mu \mathrm{M}$ arachidonic acid at room temperature for $5 \mathrm{~min}$ with constant stirring. $\left[1-{ }^{14} \mathrm{C}\right]$-Labeled arachidonic acid (GE Healthcare) was used in 1-ml incubations. HpETEs were reduced to corresponding hydroxy acids (HETEs) with $10 \mathrm{~mm} \mathrm{SnCl}_{2}$, the mixture was acidified with $\mathrm{KH}_{2} \mathrm{PO}_{4} / \mathrm{HCl}(1: 1)$ to $\mathrm{pH} 6$ and the products were extracted using ethyl acetate. Incubation products $(10-20 \mathrm{ml}$ volumes) were purified prior to HPLC analysis using thin layer chromatography: the extract was applied on a silica gel plate, eluted with a hexane/ethyl acetate/acetic acid (3:4: 0.05 ) mixture, and the product band was determined using UV light $(254 \mathrm{~nm})$ and extracted with methanol.

For kinetic studies, wild-type enzyme and selected mutants were purified on an ÄKTA FPLC system as described above. Conjugated diene formation was monitored on a UV-1601 spectrophotometer (Shimadzu) at $236 \mathrm{~nm}$. Reactions of $1 \mathrm{ml}$ (50 mM Tris- $\mathrm{HCl}, \mathrm{pH} 8.0,100 \mathrm{~mm} \mathrm{NaCl}, 2 \mathrm{~mm} \mathrm{CaCl}_{2}, \sim 60 \mu \mathrm{M}$ liposome) were performed in a thermostatted $\left(20^{\circ} \mathrm{C}\right)$ cuvette with continuous stirring. The concentration of arachidonic acid (Cayman) was varied from 2 to $200 \mu \mathrm{M}$. The reaction was initiated by adding $6 \mathrm{~nm}$ wild-type enzyme, or up to $32 \mathrm{~nm}$ for the less active mutants. The reaction velocity was determined from the slope of the linear portion of the curve. $K_{m}$ and $k_{\text {cat }}$ values were obtained by nonlinear regression analysis with the Michaelis-Menten equation. As $11 R$-LOX exhibits very strong substrate inhibition and, thus far, no suitable kinetic model has been derived, only the ascending part of the curve $(2-30 \mu \mathrm{M}$ AA) was used for fitting.

HPLC-MS Analysis-Catalysis products were analyzed by reverse phase HPLC using an Agilent Eclipse $3.5 \mu \mathrm{m} 150 \times$ 2.1-mm ODS column thermostatted at $35^{\circ} \mathrm{C}$. The sample was eluted isocratically with methanol/water/acetic acid (75:25: $0.01, \mathrm{v} / \mathrm{v} / \mathrm{v}$ ) at $0.25 \mathrm{ml} / \mathrm{min}$ on an Agilent 2200 Series HPLC system. Products were detected using a diode array detector monitoring wavelengths $210-280 \mathrm{~nm}$, followed by an Agilent LC/MSD Trap XCT mass spectrometer. The MS/MS spectra of arachidonic acid derivates were obtained in negative mode using an APCI interface.

$\left[1-{ }^{14} \mathrm{C}\right]$-Labeled products were additionally analyzed using a Radiomatic 500TR Flow Scintillation Analyzer (Packard Bioscience) preceded by an Agilent Eclipse $5 \mu \mathrm{m} 150 \times 4.6-\mathrm{mm}$ ODS column thermostatted at $35^{\circ} \mathrm{C}$ and a diode array detector. The same eluent was used at a flow rate of $1 \mathrm{ml} / \mathrm{min}$. 


\section{TABLE 1}

Data collection and refinement statistics

\begin{tabular}{|c|c|}
\hline Data collection & \\
\hline Space group & $\mathrm{C} 2$ \\
\hline \multicolumn{2}{|l|}{ Cell dimensions } \\
\hline$a, b, c(\AA)$ & 114.80148 .71117 .33 \\
\hline$\alpha, \beta, \gamma\left({ }^{\circ}\right)$ & 90.00119 .1690 .00 \\
\hline Resolution $(\AA)$ & $36.48-2.47(2.54-2.47)^{a}$ \\
\hline$R_{\text {sym }}^{b}$ & $0.072(0.474)$ \\
\hline$I / \sigma I$ & $10.1(1.7)$ \\
\hline Completeness (\%) & $97.1(84.6)$ \\
\hline Redundancy & $3.0(2.3)$ \\
\hline \multicolumn{2}{|l|}{ Refinement } \\
\hline Resolution $(\AA)$ & $36.48-2.47$ \\
\hline No. of reflections & 57,423 \\
\hline$R_{\text {work }} / R_{\text {free }}{ }^{c}$ & $0.2019 / 0.2281$ \\
\hline \multicolumn{2}{|l|}{ No. of atoms } \\
\hline Protein & 10,880 \\
\hline Iron & 2 \\
\hline Sucrose & 46 \\
\hline Water & 482 \\
\hline \multicolumn{2}{|l|}{$B$-factor $\left(\AA^{2}\right)$} \\
\hline Protein & 42.9 \\
\hline Iron & 36.3 \\
\hline Sucrose & 56.9 \\
\hline Water & 39.0 \\
\hline \multicolumn{2}{|c|}{ Root mean square deviation } \\
\hline Bond lengths $(\AA)$ & 0.005 \\
\hline Bond angles $\left(^{\circ}\right)$ & 0.6 \\
\hline \multicolumn{2}{|c|}{$\begin{array}{l}{ }^{b} R_{\text {sym }}=\Sigma_{h} \Sigma_{l}\left|I_{h l}-\left\langle I_{h}\right\rangle\right| / \Sigma_{h} \Sigma_{l}\left\langle I_{h}\right\rangle \text {, where } I_{h l} \text { is the intensity of the } l \text { th observation } \\
\text { and }\left\langle I_{h}\right\rangle \text { is the mean intensity of the reflection } h \text {. } \\
{ }^{c} R=\Sigma|| F_{o}|-| F_{c} \| / \Sigma\left|F_{o}\right| \text {, where } F_{o} \text { and } F_{c} \text { are the observed and calculated struc- } \\
\text { ture factor amplitudes, respectively. } R_{\text {free }} \text { was calculated using } 3.33 \% \text { of the total } \\
\text { reflections. }\end{array}$} \\
\hline
\end{tabular}

To analyze the chirality of HETEs, the products were purified in a normal phase HPLC system using a Phenomenex Luna 5 $\mu \mathrm{m} 250 \times 4.6-\mathrm{mm}$ Silica column in isopropyl alcohol $(1 \%$ $\left.\mathrm{H}_{2} \mathrm{O}\right) /$ hexane $(7: 93, \mathrm{v} / \mathrm{v})$ at $1 \mathrm{ml} / \mathrm{min}$. HETEs were methylated using diazomethane and analyzed using a Chiralcel OD-H $250 \times 4.6-\mathrm{mm}$ column in $0.7 \%$ isopropyl alcohol (dry), $0.7 \%$ methanol, hexane $(\mathrm{v} / \mathrm{v} / \mathrm{v})$ at $1 \mathrm{ml} / \mathrm{min}$.

Liposome Preparation-Small unilamellar vesicles were prepared from L- $\alpha$-phosphatidylcholine, L- $\alpha$-phosphatidylethanolamine, and $\mathrm{L}-\alpha$-phosphatidylserine (Avanti Polar Lipids). A mixture of phosphatidylcholine/phosphatidylethanolamine/ phosphatidylserine (40:30:30 $\mathrm{mol} \%$ ) in chloroform was dried in a round-bottom flask using a nitrogen stream to form a thin film and was incubated in vacuum for $1 \mathrm{~h}$ at room temperature. Buffer (50 mm Tris- $\mathrm{HCl}, 100 \mathrm{~mm} \mathrm{NaCl}, \mathrm{pH} 8.0$ ) was added to the dried lipids and the film was soaked for $1 \mathrm{~h}$. The suspension was shaken vigorously, sonicated $15 \times 5 \mathrm{~s}$ on a Torbéo 36810 Series cell disruptor (Cole Parmer) with 1-min intervals at the setting of 5 in a water bath at room temperature. The sonicate was centrifuged at $13,000 \times g$ for $20 \mathrm{~min}$ at $4{ }^{\circ} \mathrm{C}$. The supernatant was saved and stored at $4{ }^{\circ} \mathrm{C}$.

\section{RESULTS}

Overall Structure-The crystal structure of $11 R$-LOX in a calcium-free environment was refined at $2.47 \AA$ with $R_{\text {work }}$ and $R_{\text {free }}$ values of 0.20 and 0.23 , respectively (Table 1 ). The protein crystallized in space group $\mathrm{C} 2$ with two molecules in the asymmetric unit. Phasing was done with molecular replacement using $P$. homomalla $8 R$-LOX (PBD code 2 fnq) as a template. A total of $96.1 \%$ of the residues are in the favored region of the Ramachandran plot and there are no outliers according to MolProbity validation (48).
Like the majority of lipoxygenases, $11 R$-LOX consists of two distinct domains: the N-terminal C2-like PLAT domain (residues $1-115$ ) and a larger mainly $\alpha$-helical catalytic domain (residues 129-679), which are connected by a small linker region (residues 116-128). The catalytic domain contains the nonheme iron, which is coordinated by three highly conserved histidines, $\mathrm{His}^{373}$ His $^{378}$, and $\mathrm{His}^{556}$, and the carboxylate group of the C-terminal Ile ${ }^{679}$. In general, the structure is very similar to that of the $8 R$-LOX domain of $P$. homomalla allene oxide synthase-LOX fusion protein, a root mean square deviation of $644 \mathrm{C}_{\alpha}$ pairs being $1.37 \AA$. The greatest differences are found in the putative entrance to the active site, which more closely resembles the recently published human Stable-5-LOX (22). Similarly to 5-LOX, the $\alpha 2$ helix of $11 R$-LOX that covers the putative entrance is only about 2 turns long and is flanked by loops and small $33_{10}$-helices. It should also be mentioned that the overall similarity between the $11 R$ - and 5 -LOX is very high (root mean square deviation of $641 \mathrm{C}_{\alpha}$ pairs is $1.49 \AA$ ).

Another heterogeneous region includes the putative $\mathrm{Ca}^{2+}$ binding sites in the PLAT domain. The PLAT domain is a $\beta$-sandwich consisting of two antiparallel 4 -strand $\beta$-sheets. At the sheets' ends proximal to the catalytic domain (opposite to the $\mathrm{N}$ terminus) there are four loops that connect the two sheets, three of the loops being rather extensive, this is the region that contains the $\mathrm{Ca}^{2+}$-binding sites. The electron density map is less clear in the region of the PLAT domain, which is characterized by higher mean $B$-factors, $37.3 \AA^{2}$ for the catalytic domain versus $70.5 \AA^{2}$ in the PLAT domain. The least well defined densities are found in the putative calcium-binding loops, especially residues $\mathrm{His}^{43}-\mathrm{Glu}^{47}$ and $\mathrm{Gly}^{73}-\mathrm{Lys}^{77}$; whereas main chain density is not ambiguous, several side chains were modeled primarily according to optimal geometry (side chains present at $\geq 0.5 \sigma$ ). For refinement, all occupancies were set to 1 . The apparent mobility of these residues is described by their elevated $B$-factors.

Dimerization-Size exclusion chromatography indicated that $11 R$-LOX appears as a dimer in a calcium-free buffer. The purified enzyme eluted with aldolase $(158 \mathrm{kDa})$, which is double the molecular mass of the recombinant protein $(79 \mathrm{kDa}$ ) (supplemental Fig. S1). Based on ultrafiltration assays, it was previously concluded that $11 R$-LOX is in a monomeric state in solution: in calcium-free conditions the enzyme passed a filter with a 100-kDa cutoff without major losses (25). The findings presented here clearly dispute those claims. In the presence of 10 $\mathrm{mm} \mathrm{CaCl} 2$, however, size exclusion chromatography analysis indicated the formation of large aggregates, as the protein eluted with the void volume (data not shown). Similar results were obtained using ultrafiltration (25). Potential dimerization interfaces were searched among the crystal contacts using PISA (45), but according to the criteria established by the algorithm, no significant assemblies were found.

Substrate Channel and Its Entrances-There is an array of consecutive, mostly hydrophobic cavities concealed in the catalytic domain alongside the coordinated non-heme iron (Fig. 2 ). These cavities are covered by a conserved arched helix $(\alpha 10-\alpha 11$ in G. fruticos $a)$, and the potential entrances on either side are blocked by short helices and loops. The arched helix harbors the $R / S$-stereospecificity determinant Gly ${ }^{416}$ (34). 


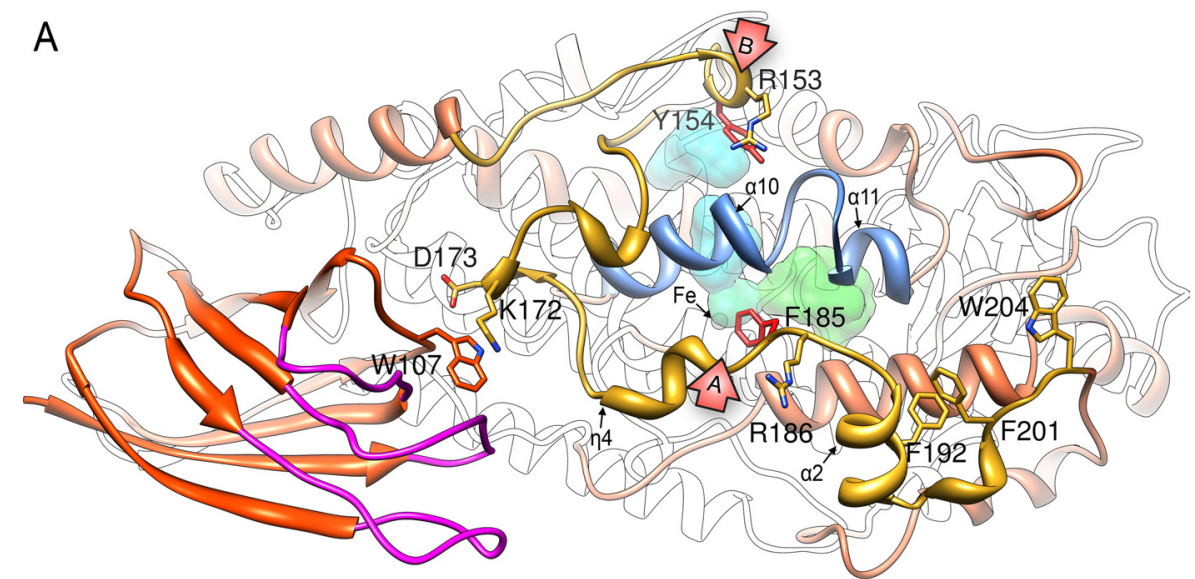

B

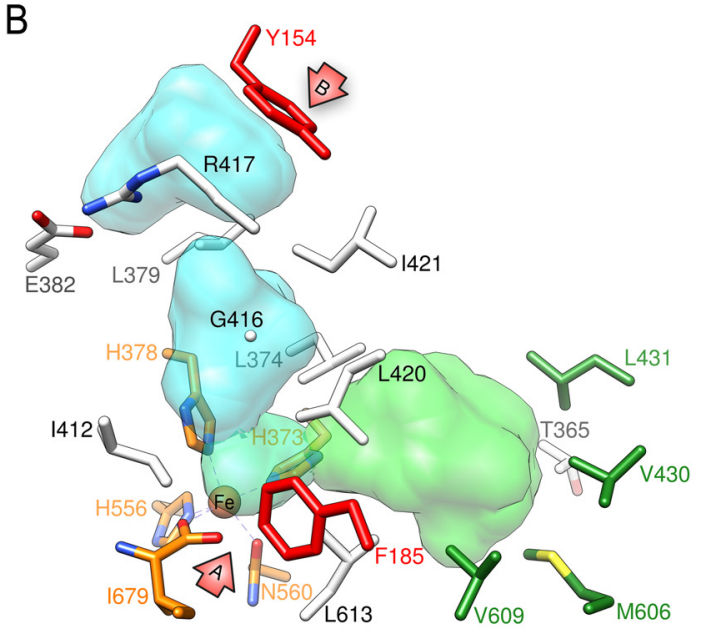

C $\mathrm{Y} 154$
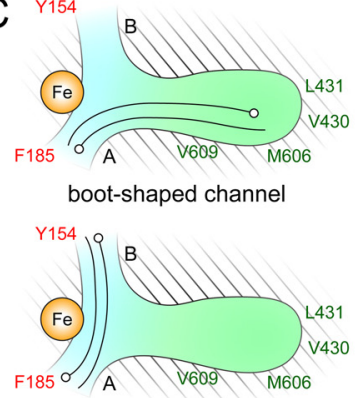

U-shaped channel

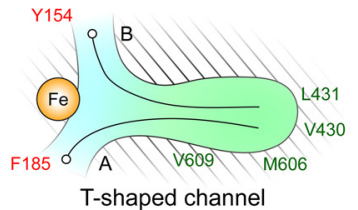

FIGURE 2 . The active site and its accessibility. $A$, the active site with the non-heme iron (sphere) and substrate binding cavities (cyan and green surfaces) are covered by the conserved arched helix $\alpha 10-\alpha 11$ (blue). Potential entrances A and B (arrows) are blocked by Phe ${ }^{185}$ and Tyr ${ }^{154}$ (red residues), respectively. Both have an arginine in the vicinity that could stabilize the carboxylate head of the fatty acid substrate. The entrances are covered by the lid segment (gold) that interacts with the PLAT domain (orange) near the loops, which contain the putative $\mathrm{Ca}^{2+}$-binding sites (magenta), via a $\pi$-cation bridge $\left(\operatorname{Trp}^{107}-\right.$ Lys $^{172}$ ). Additionally, there are hydrophobic residues in the C-terminal part of the lid that could bind the lipid membrane. $B$, in the active site, the non-heme iron is coordinated by highly conserved residues (orange). The volume of the hydrophobic pocket (light green) has been found to be important in catalysis specificity $(7,12)$. Residues marked in green were mutated in this study to investigate that hypothesis. Another set of cavities (cyan) could give access to the active site via the alternative entrance B. C, schematic depictions of hypothesized substrate-binding channels and substrate orientations (viewing angle is analogous to panels $A$ and $B$ ). The boot-shaped cavity is defined as a passage from entrance $A$ to the bottom of the hydrophobic pocket $(7,12)$. The U-shaped channel would stretch between the two entrances (18). Yet another possibility is that the fatty acid tail is always bound into the hydrophobic pocket, but either one of the entrances is used depending on the enzyme isoform, this yields the T-shaped channel.

There is a small confined chamber (about $34 \AA^{3}$ ) next to the catalytic iron that is surrounded by several conserved aliphatic residues, which have been thoroughly discussed in $P$. homomalla $8 R$-LOX by Neau et al. (18). Of those residues, $\mathrm{Leu}^{374}$, Leu ${ }^{420}$, and Leu ${ }^{613}$ form an orifice that leads to the largest cavity $\left(188 \AA^{3}\right.$ ), which is located under the arched helix toward the "rear" end of the enzyme (away from the PLAT domain). The bottom of this cavity is composed of residues $\mathrm{Thr}^{365}, \mathrm{Val}^{430}$, and $\mathrm{Val}^{609}$, which coincide with the regiospecificity determinants described for the boot-shaped channel in 12/15-LOX (7); Leu ${ }^{431}$, also a regiospecificity determinant of some LOXs $(8,12)$; and Met $^{606}$, a position claimed to be relevant in the binding orientation of the fatty acid substrate (49). On one side of the arched helix, the entrance to the active site chamber is blocked by Phe ${ }^{185}$ that sits on a loop between helices $\eta 4$ ( $3_{10}$-helix) and $\alpha 2$. On the other side, a gap between Leu ${ }^{374}$, $\mathrm{Ile}^{412}$, and Leu ${ }^{420}$ leads to a pair of cavities (95 and $113 \AA^{3}$ ) that also reach toward the protein surface. These cavities are lined perpendicularly to the largest one, and are separated from each other by a constriction formed by $\mathrm{Leu}^{379}$, $\mathrm{Ile}^{421}$, and a conserved salt bridge $\mathrm{Glu}^{382}-\mathrm{Arg}^{417}$, that participates in lodging the arched helix. Access on this side is obstructed by $\mathrm{Tyr}^{154}$ and the loop where that residue is situated.

Let us call the orifices blocked by $\mathrm{Phe}^{185}$ and $\mathrm{Tyr}^{154}$ entrances $A$ and $B$, respectively. Both of these entrances have a positively charged residue in the vicinity, which could neutralize the carboxylate group of a fatty acid, and therefore, aid to position the substrate for catalysis: these are $\mathrm{Arg}^{186}$ for entrance $\mathrm{A}$, and $\mathrm{Arg}^{153}$ for $\mathrm{B}$. It is interesting to note that the chain fragments that constitute the lids over both entrances interact with the PLAT domain, there is a $\pi$-cation interaction between $\operatorname{Trp}^{107}$ and $\operatorname{Lys}^{172}$, as well as an $\mathrm{H}$-bond connecting the main chain N-H of $\operatorname{Trp}^{107}$ with $\mathrm{Asp}^{173}$ (Fig. $2 A$ ). The lids of entrances $\mathrm{A}$ and $\mathrm{B}$ are on the $\mathrm{C}$ - and $\mathrm{N}$-terminal sides of the interface, respectively. Therefore, either one of the entrances could be regulated via this bridge. The $\pi$-cation bond appears 


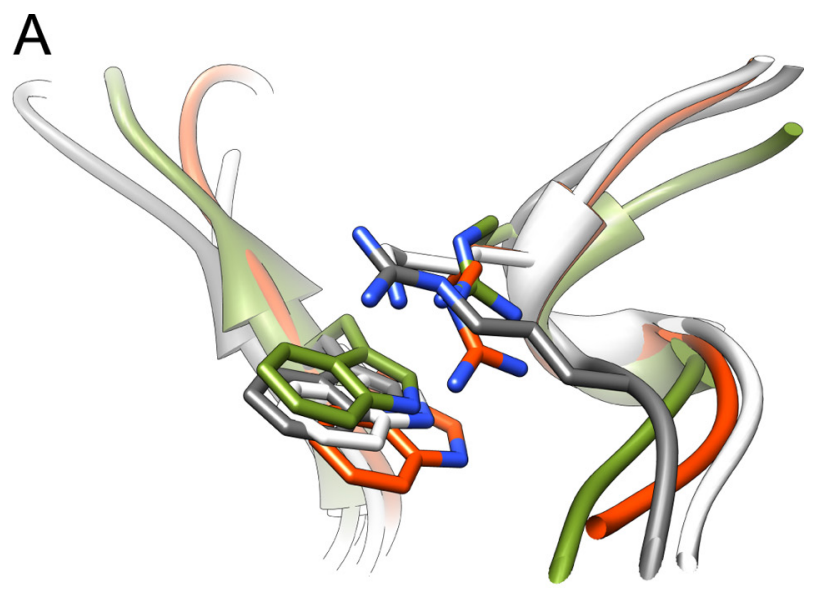

B

\begin{tabular}{|c|c|c|c|c|}
\hline $11 R-L$ & & $\beta 7$ & & $\begin{array}{c}\eta 3 \\
\text { Q }\end{array}$ \\
\hline 11R-LOX & 97 & $\mathrm{P} C \mathrm{Y}$ RWV & 170 & $\mathrm{~L} P \mathrm{~K} \mathrm{DVQF}$ \\
\hline AOSL_PLEHO & 472 & $\mathrm{P} C \mathrm{~F}$ R W V & 537 & L P R D Q F \\
\hline LOX15_PONAB & 89 & GDEVRF $\mathrm{P} C \mathrm{Y}$ RWV & 160 & L P V D ER F \\
\hline LOX15_HUMAN & 89 & GDEVRF $P$ C $Y$ RWV & 160 & L P VDERF \\
\hline LOX12_PIG & 90 & GDEFR F P C $Y$ RWV & 1 & L P V D E R F \\
\hline LOX12_BOVIN & 90 & GNEFRFPCY R V V & & L P V D E R F \\
\hline LOX12_RABIT & 90 & E D K YWF P C Y RWV & & L P V D E R F \\
\hline LOX15_RABIT & 90 & E D K Y W P C Y RWV & & L P V D E R F \\
\hline LX12L MOUSE & 90 & G SEYTF $P$ C $Y$ RWV & & $\mathrm{L}$ P V D Q R F \\
\hline LX12L_RAT & 90 & $\begin{array}{llllll}\mathrm{E} Y \mathrm{M} & \mathrm{P} & \mathrm{C} & \mathrm{Y} & \mathrm{R} W \mathrm{~V} \\
\end{array}$ & & $\mathrm{~L} P \mathrm{D} \mathrm{DQR}$ \\
\hline LX12E MOUSE & 89 & QGEAF F P C Y SWV & & L $P R N Q R F$ \\
\hline LOX12_HUMAN & 89 & $\begin{array}{llllll}\mathrm{V} V \mathrm{~F} & \mathrm{P} & \mathrm{Y} & \mathrm{R} W \mathrm{~V} \\
\end{array}$ & & L P P N M R F \\
\hline LOX12 MOUSE & 89 & $\begin{array}{llllll}\text { E A V } & F & P & C & Y & R\end{array}$ & & L P P N M R F \\
\hline LX15B_MOUSE & 101 & $\begin{array}{lllll}\mathrm{A} L \mathrm{H} & \mathrm{F} & \mathrm{P} & \mathrm{Y} & \mathrm{QWL}\end{array}$ & & L D L N I K Y \\
\hline LX15B_RAT & & $\triangle \mathrm{LR} P \mathrm{P} \mathrm{Y} \mathrm{Q} \mathrm{WL}$ & & $\mathrm{L} D \mathrm{D} N \mathrm{~N}$ K Y \\
\hline LX15B_HUMAN & 100 & $\mathrm{IL} \mathrm{F} \mathrm{P} C \mathrm{Y} \mathrm{QWL}$ & & L E I N I KY \\
\hline LX12B_MOUSE & 95 & 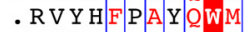 & & $\mathrm{L} N \mathrm{~N}$ L R F \\
\hline LX12B_RAT & 9 & Y H $\mathrm{F} \mathrm{P} \mathrm{A} Q \bar{Q}$ & & LN L N L R F \\
\hline LX12B_HUMAN & 95 & Y H $\mathrm{F}$ P $\mathrm{A} \mathrm{Y} \mathrm{QW}$ & & LN LN L R Y \\
\hline LOXE3_HUMAN & 9 & $S H F C Y Q n$ & & ME P N V R Y \\
\hline LOXE3-MOUSE & 9 & $\begin{array}{llllll}V & \mathrm{~F} & \mathrm{P} & \mathrm{C} & \mathrm{Y} & \mathrm{Q} W \mathrm{I} \\
\end{array}$ & & ME P N I R Y \\
\hline LOX5_EAT & 93 & I E $\mathrm{F}$ P $\mathrm{C}$ Y $\mathrm{R} W \mathrm{I}$ & & L P R I Q F \\
\hline LOX5_MOUSE & 9 & I E $\mathrm{F}$ P $\mathrm{C}$ Y $\mathrm{R}$ W I & & L P R I Q F \\
\hline LOX5_MESAU & 9 & I E $F$ P $C$ Y R R I & & LPRP I QF \\
\hline LOX5_HUMAN & 93 & I E $\mathrm{F} P \mathrm{P} Y \mathrm{RW}$ I & & L P R I Q F \\
\hline LOX2_SOYBN & 150 & T I R $F$ V C N SWV & & VPR D E N F \\
\hline LOX1_SOYBN & 120 & T I R F V C N SWV & & V P R D E N L \\
\hline LOXX_SOYBN & 146 & H G T I E F V C N SWV & & V P R D E N F \\
\hline LOX4-SOYBN & & T I H F V C N SWV| & & $\mathrm{L} P \mathrm{R} D \mathrm{DEF}$ \\
\hline LOX3-SOYBN & & $\mathrm{S} I \mathrm{H}|\mathrm{F}| \mathrm{V}|\mathrm{C} \mathrm{N}| \mathrm{SW} \mathrm{I}$ & & L P R D A A F \\
\hline LOXA_SOLLC & 134 & H G K V H F C N SWV & & VPRP E R F \\
\hline LOX1_ARATH & 136 & H G R V H Y I C N SW I & & $\mathrm{V} P \mathrm{P}$ D E R F \\
\hline LOX2_ARATH & 175 & . G S I T $F \mathrm{~T}$ C SWV & 297 & V P R DEEF \\
\hline
\end{tabular}

FIGURE 3. The conserved $\pi$-cation bridge binds the regulatory PLAT and the catalytic domains. $A$, superposition of $11 R$-LOX (white), rabbit 12/15-LOX (gray), human 5-LOX (orange), and soybean LOX-1 (green) reveals the common interface. $B$, partial sequence alignments of the PLAT domain and the lid that establish the $\pi$-cation bridge. The PLAT domain $\operatorname{Trp}^{107}$ is invariant, the cationic residue can be found in either of the two positions (blue arrows).

to be conserved as it is present in all published lipoxygenase crystal structures $(18,20,22,50-53)$ (Fig. 3A). The PLAT domain $\operatorname{Trp}^{107}$ is invariant among studied LOXs and is a part of the conserved sequence FPCYRW on the $\beta 7$ strand of animal LOX (28). The cationic residue of the catalytic domain (Lys ${ }^{172}$ in $11 R$-LOX) is more variable, but can still be found in either of the two positions shown on the alignment (Fig. $3 B$ ).

$\mathrm{Ca}^{2+}$-binding Sites-The 11R-LOX crystals were obtained in calcium-free conditions, but for catalytic activity, the presence of $\mathrm{Ca}^{2+}$ is a must. When compared with available structures of $\mathrm{Ca}^{2+}$-PLAT complexes, the $\mathrm{Ca}^{2+}$-binding loops of the apo-domain in $11 R$-LOX differ significantly. The PLAT domains of coral $8 R$-LOX (21) and gangrene $\alpha$-toxin (54) both contain

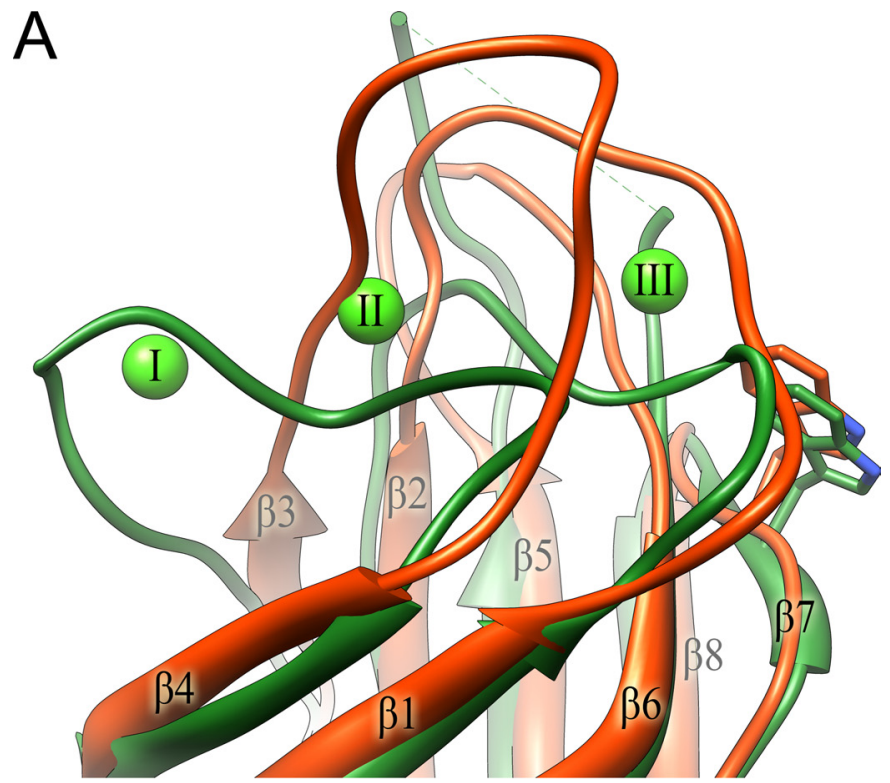

D
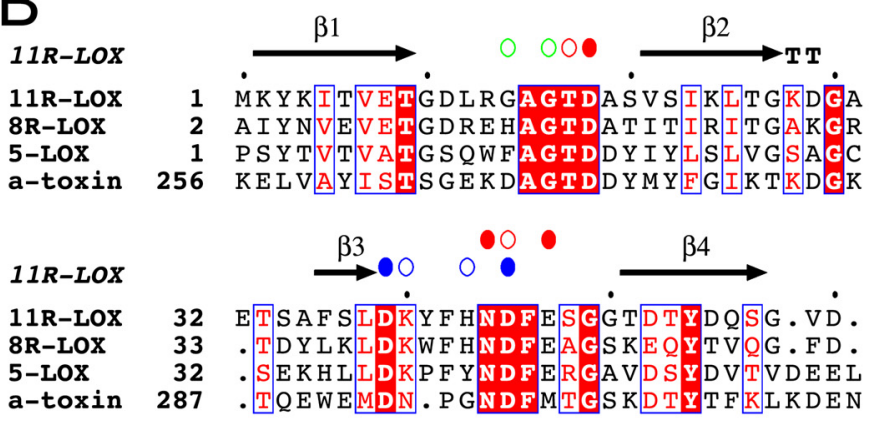

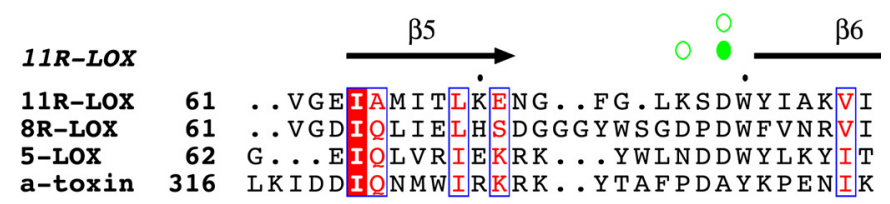

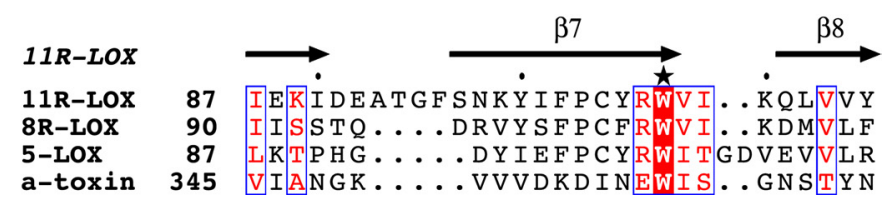

FIGURE 4. The PLAT domain and putative $\mathrm{Ca}^{2+}$-binding sites. $A$, superposition of the coral $8 R$-LOX Ca ${ }^{2+}$-PLAT complex (green) and the $11 R$-LOX apoPLAT (orange). The invariant Trp is situated on the $\beta 7$-strand right next to site III. $B$, conservation of binding sites, conserved residues are in red. 11R-LOX, $8 R$-LOX, and gangrene $\alpha$-toxin are aligned according to a structural superposition; human 5-LOX is aligned according to sequence. Residues that constitute sites I (blue), II (red), and III (green) in 8R-LOX and $\alpha$-toxin are denoted by circles (empty if participates by main chain, filled if by side chain atom). The invariant Trp is indicated by a star.

three occupied binding sites, these are formed by three adjacent loops and are well conserved both in sequence and structure (21). All three sites are also preserved in the $11 R$-LOX sequence, yet are absent in the tertiary structure (Fig. 4). The first $\mathrm{Ca}^{2+}$ complex is formed by a turn in the $\beta 3-\beta 4$ loop; in the apo-PLAT domain the turn is missing, and instead, there is an extra $\beta$-strand-like segment. The second site is situated between another turn in the $\beta 3-\beta 4$ loop and $\beta 1-\beta 2$ loop; again, the loops in $11 R$-LOX are arranged differently making a 


\section{Regulation of 11R-Lipoxygenase Catalysis}

\section{TABLE 2}

Positional specificity of $11 R$-LOX (\%)

Arachidonic acid was incubated with the bacterial crude lysate, reaction products were analyzed by RP-HPLC-MS. Chromatograms and MS/MS spectra are provided in supplemental Fig. S3 and S4.

\begin{tabular}{lllll}
\hline Enzyme & 15-HpETE & 11-HpETE & 8(/12)-HpETE & 5-HpETE \\
\hline WT & 2 & 98 & $\mathrm{ND}^{a}$ & ND \\
V430A & 1 & 99 & ND & ND \\
V609A & 8 & 91 & 1 & ND \\
L431A & 3 & 87 & 10 & ND \\
M606A & 2 & 89 & 9 & ND \\
V609W & 23 & 69 & $3^{b}$ & 5
\end{tabular}

$b$ 8- and 12-HETE did not separate in the HPLC system, but both derivates were detected by MS for V609W.

smoother curve and reaching further away from the $\beta$-sandwich core. The same goes for the third site that lies between a turn in the $\beta 1-\beta 2$ loop and the $\beta 5-\beta 6$ loop. Site III is also the hardest to detect by sequence comparison as it is mostly defined by main chain atoms. Fig. 4 illustrates that the $\mathrm{Ca}^{2+}$-binding sites are intertwined; therefore, a cascade of conformational changes could occur upon metal chelation. The aforementioned $\operatorname{Trp}^{107}$ is right next to site III and makes contacts with residues that define the site in both apo- and holo-PLAT domains. This suggests it could be communicating the allosteric effect that occurs upon calcium and membrane binding in the PLAT domain to the lid segment.

Site-directed Mutagenesis of Substrate Channel-Several residues were mutated in the largest of the internal cavities to study its intrinsic role in the specificity of catalysis. Bulky, hydrophobic $\mathrm{Val}^{430}$, $\mathrm{Leu}^{431}$, Met ${ }^{606}$, and $\mathrm{Val}^{609}$ were substituted with a compact alanine to deepen the boot-shaped channel, and potentially alter the regiospecificity of the enzyme, as has been previously shown by Kühn et al. (7). In the case of $11 R$-LOX, the additional space was expected to cause a frameshift of substrate binding, resulting in a novel 8-LOX activity, unseen in the wild-type. The V430A and V609A substitutions failed to alter the position of hydrogen abstraction, although the corresponding residues have been described as regiospecificity determinants for rabbit 12/15-LOX (11) and many others (12) (full sequence alignment is provided in supplemental Fig. S2). Rather, the V609A mutant suffered from general loss of positional control, exhibiting increased 15-HpETE production (Table 2). On the other hand, modest 8-LOX activity was observed with L431A and M606A mutants, reaching up to $10 \%$ of 8 -HpETE production. Further kinetic studies of those enzymes showed that there was no remarkable change in substrate affinity $\left(K_{m}\right)$ (Table 3). However, the catalysis efficiency $\left(k_{\text {cat }} / K_{m}\right)$ of the L431A mutant was only one-fourth of the wildtype as the turnover rate $\left(k_{\text {cat }}\right)$ had dropped. One possible interpretation of this data is that the substrate cannot align in an orientation appropriate for hydrogen abstraction as the hydrophobic pocket has a role in substrate positioning. Granted, the data do not rule out an effect on the catalytic machinery itself, but the fact that enzyme retains catalytic activity might suggest that the iron coordination sphere remains intact. Moreover, the residue at this position varies significantly among LOX isoforms so it is in all likelihood not an essential element of the core LOX fold.

\section{TABLE 3}

Kinetic properties of wild-type $11 R$-LOX and selected mutants

All enzymes were readily purified and analyzed as described under "Experimental Procedures."

\begin{tabular}{llll}
\hline Enzyme & \multicolumn{1}{c}{$\boldsymbol{k}_{\text {cat }}$} & \multicolumn{1}{c}{$\boldsymbol{K}_{\boldsymbol{m}}$} & $\boldsymbol{k}_{\text {cat }} / \boldsymbol{K}_{\boldsymbol{m}}$ \\
\hline & \multicolumn{1}{c}{$\boldsymbol{s}^{-1}$} & \multicolumn{1}{c}{$\boldsymbol{\mu M}_{\mathrm{M}}$} & \\
WT & $310.7 \pm 24.6$ & $12.3 \pm 2.2$ & 25.2 \\
L431A & $50.6 \pm 3.3$ & $7.8 \pm 1.4$ & 6.5 \\
M606A & $398.0 \pm 20.8$ & $13.7 \pm 1.5$ & 29.0 \\
V609W & $5.8 \pm 0.6$ & $12.4 \pm 3.0$ & 0.5 \\
\hline
\end{tabular}

Although the data display a trend, these studies do not rule out the use of the alternative U-shaped channel (Fig. 2C). To find more substantial evidence to differentiate between the channels, $\mathrm{Val}^{609}$, which lies near the proximal side of the hydrophobic pocket, was substituted with a large tryptophan to block the distal end of the cavity, and propagate the usage of the U-shaped channel. As a consequence, the catalytic efficiency of the enzyme plunged 50-fold, but surprisingly, the $K_{m}$ remained unaffected despite the dramatic reduction in binding space that such a mutation should have caused. Apparently, the loss of activity was entirely due to the diminished turnover rate (Table 3 ). Reaction specificity suffered greatly, as well, as the share of 11-HpETE dropped down to $69 \%$ and a multitude of by-products (15/5/8/12-HpETE in descending order by proportion) was formed (Table 2). The chirality of the three major products of V609W mutant, 11/15/5-HpETE, was determined using chiral phase HPLC, to confirm the substrate orientation in the active site. Practically pure $11 R$ and $5 S$ products were detected, oxygenation at $\mathrm{C} 15$ created an $R / S$ (35:65) mixture (data not shown). The formation of $5 S$-HpETE intimates a head-first binding if entrance $\mathrm{A}$ is considered as the point of entry, whereas for $11 R$-HpETE, tail-first orientation has been suggested (25).

The interpretation of these data is not straightforward. If one invokes the use of the boot-shaped cavity, the residual activity of the V609W mutant may be a result of incomplete closure of the cavity and a motional flexibility to allow room for substrate entry despite the bulky tryptophan (Fig. 2C). On the other hand, if the fatty acid binds into the $U$-shaped channel, the role of the hydrophobic pocket may be to provide the flexibility necessary for the substrate to product transition. This would easily explain the unchanged $K_{m}$. Nevertheless, the various regiospecificities of distinct LOXs must somehow be reflected by their binding sites (e.g. different cavity volumes). The U-shaped channel is highly conserved, as emphasized by Neau et al. (18), but the invariant amino acids alone cannot explain the distinct products among lipoxygenases. Those side chains that impart specificity would be expected to lie outside the cluster of conserved amino acids. The hydrophobic pocket fulfills that criterion, and binding of AA in that cavity is supported by product shifts in L431A and M606A mutants.

\section{DISCUSSION}

Allosteric Lid Segment-The substrate channel entrance A of $11 R$-LOX is blocked by $\mathrm{Phe}^{185}$. Interestingly, a similar element, a Phe-Tyr "cork," has been described in human 5-LOX (22). This cork is situated where the other LOX crystal structure models are open to allow access to the catalytic site. In these 


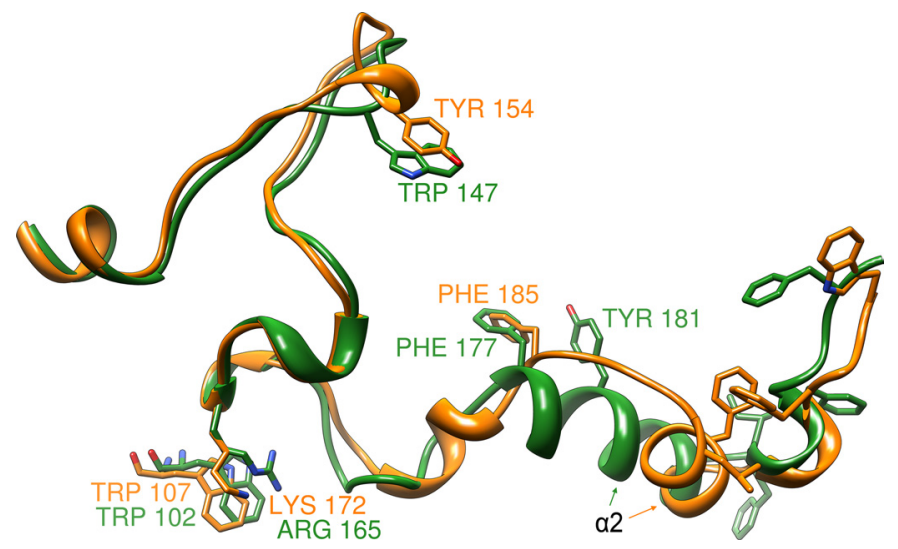

FIGURE 5. Superposed 11R-LOX (orange) and human 5-LOX (green) lid segments. In 5-LOX, entrance A is blocked by a Phe ${ }^{177}-$ Tyr $^{181}$ cork (22), the $11 R$-LOX counterpart of which is $\mathrm{Phe}^{185}$. For entrance $\mathrm{B}$, the corks are Trp ${ }^{147}$ and $\mathrm{Tyr}^{154}$, respectively. Both structures include the conserved $\pi$-cation bridge and several hydrophobic residues in the C-terminal part, which could anchor into the lipid membrane.

two structures, however, the $\alpha 2$ helix is considerably shorter and is flanked by loops and $3_{10}$-helices forming a lid that covers entrance A (Fig. 5). In the N-terminal end of this motif is the conserved $\pi$-cation bridge $\left(\operatorname{Trp}^{107}-\right.$ Lys $^{172}$ ) that connects the PLAT and the catalytic domain. The $\pi$-cation bridge is preceded in turn by the lid of entrance B, with $\mathrm{Tyr}^{154}$ blocking the access. The corresponding cork in human 5-LOX is $\operatorname{Trp}^{147}$, and again, the similarity between the coral and human enzyme lids is remarkable. Notably, this is the entrance Gilbert et al. (22) have suggested to be utilized in 5-LOX, as opening it requires only a rotamer flip, and this way the substrate can enter the channel "tail first." The stereochemistry of the products of 5and $11 R$-LOX suggests that AA is bound in inverse orientations in these enzymes: may it be a result of the substrate entering the active site in inverse orientation using the same orifice or the utilization of different entrances. In either case, access to the catalytic site in both enzymes requires a conformational change, an opening of the lid. The structure of $11 R$-LOX can provide a stable framework for understanding the relationship between $\mathrm{Ca}^{2+}$-dependent membrane binding and lid opening.

It has been speculated that the interface of PLAT and catalytic domains, including the conserved FPCYRW fragment on the $\beta 7$ strand, might be involved in an allosteric regulatory mechanism, transmitting a conformational change in the PLAT domain induced by calcium and membrane binding to the lid component in the catalytic domain (28). We propose, that the conserved $\pi$-cation bond could be mediating this interaction, as it stands right between the $\mathrm{Ca}^{2+}$-binding sites and the allosteric lid. The different regulatory properties of various lipoxygenases (e.g. the necessity of calcium and membranes for $11 R$ LOX catalysis) can be explained by differing conditions that are needed to set off the cascade of conformational changes, which among other contributors depend strongly on the structure of the $\mathrm{Ca}^{2+}$-binding loops (55). The activity that is present without any inducing factors in most LOXs can be attributed to a semi-open orifice, or possibly allosteric binding of the substrate itself. Additionally, in human 5-LOX the FPCYRW fragment has been shown to be involved in the binding of the coactosinlike protein, which promotes leukotriene formation (56).
Although the exact mechanism of the latter is unknown, it further substantiates the regulatory role of the bridge.

In $11 R$-LOX, entrance A seems the more plausible access route for several reasons. First, the same orifice is used in rabbit $15 S$-LOX according to docking studies (14). For $11 R$ - and $15 S$ specificity, the same hydrogen must be abstracted in the initial step of catalysis; thus, substrate binding should also be identical. Second, coral 8R-LOX, the binding of which should differ from $11 R$ - and $15 S$-LOX only by "frameshift," has been suggested to employ entrance A as well (18). Another detail in favor of entrance $A$ is that there are several bulky, hydrophobic residues like Phe ${ }^{192}$, Phe $^{201}$, and $\operatorname{Trp}^{204}$ on the C-terminal end of its lid fragment, distal to the PLAT domain interface (Fig. 5). With slight conformational changes, these residues could readily anchor the catalytic domain to the lipid membrane, and facilitate an additional mechanism of lid removal. Analogous residues are present in other lipoxygenases, too, including human 5-LOX. Furthermore, the entrance A lid is followed by the putative PDZ domain, which might also contribute to allosteric regulation, making this opening the more likely candidate not only for $11 R$-LOX, but for other LOXs as well.

Additional experimental data are essential to elucidate the possible access portals in this family of enzymes. In a recent experiment, removing the entrance A cork of olive LOX1 by site-directed mutagenesis augmented the activity of the enzyme remarkably (57). A similar approach could be used in further study to determine the true substrate entrance of $11 R$ LOX, but also of other LOXs.

T-shaped Substrate Channel-In general, the $11 R$-LOX model contains a closed, roughly T-shaped system of cavities, wherein the active site iron is located at the junction of perpendicular channels, and the potential entrances for the substrate are situated at both ends of the "T-bar" (Fig. 2C). Although the channel system seems to be segmented in the model, minimal side chain movements are necessary to connect the neighboring pockets. In this system of cavities, the so called boot-shaped channel described by Kühn et al. $(7,12)$ would constitute the passage from entrance $A$ to the bottom of the hydrophobic pocket. The alternative U-shaped channel proposed by Neau et al. (18), on the other hand, would consist of a culvert stretching below the arched helix and connecting both entrances, and thus, disregarding the pocket altogether.

The results obtained by site-directed mutagenesis of $11 R$ LOX suggest that the integrity of the T-shaped channel is required for proper positioning of the substrate. The fact that L431A and M606A substitutions resulted in an 8/11-LOX, albeit with modest amounts of the 8-product, suggests that AA enters the hydrophobic pocket tail-first. This model is also supported by the dramatic reduction of catalytic activity and specificity when the pocket was blocked by the V609W substitution, even though the kinetic parameters for that mutant have left room for alternative interpretations. It is likely that in regard to substrate binding, $11 R$-LOX is analogous to the enzymes described to have a boot-shaped channel (e.g. rabbit 12/15-LOX).

The presence of cavities that connect the hypothetical entrance B with the active site still makes one question their potential role. The U-shaped channel is lined with highly con- 


\section{Regulation of 11R-Lipoxygenase Catalysis}

served Leu and Ile residues that imply a structure-functional importance. However, the highly conserved amino acids alone cannot define the different catalytic properties of lipoxygenases. And whereas the cavity that forms the B side of the T-site may provide an entry way for molecular oxygen access as suggested for soybean LOX-1 $(58,59)$, it is not clear whether leucines, as opposed to any hydrophobic amino acids, are necessary for an $\mathrm{O}_{2}$ channel. It just might be that distinct lipoxygenases each utilize the central core of the binding site, but regiospecificity is defined by the access to that core. One could imagine a theory that merges the boot- and U-shaped passages, yielding a T-shaped substrate channel. Depending on the catalytic specificity of a particular LOX, the substrate could enter tail-first utilizing either one T-bar entrances. Additional mechanisms like positively charged residues could further induce and stabilize the substrate binding. Yet, for specificity, the aliphatic tail requires the internal hydrophobic pocket. Further studies, especially co-crystallization of the enzyme with the substrate could bring more definitive answers to these matters.

Acknowledgments-We thank Cory LaCrouts for expert assistance in protein expression and purification, and Dr. David Neau in data collection. Preliminary work was performed at the Center for Advanced Microstructures and Devices (Baton Rouge), funded in part by the Louisiana Governors' Biotechnology Initiative. X-ray data were collected at Beam Line 24-ID-E of NE-CAT at the Advanced Photon Source, supported by Award RR-15301 from the National Center for Research Resources at the National Institutes of Health. Use of the Advanced Photon Source, an Office of Science User Facility operated for the United States Department of Energy (DOE) Office of Science by Argonne National Laboratory, was supported by the United States DOE under Contract DE-ACO2-06CH11357.

\section{REFERENCES}

1. Brash, A. R. (1999) Lipoxygenases. Occurrence, functions, catalysis, and acquisition of substrate. J. Biol. Chem. 274, 23679-23682

2. Pidgeon, G. P., Lysaght, J., Krishnamoorthy, S., Reynolds, J. V., O’Byrne, K., Nie, D., and Honn, K. V. (2007) Lipoxygenase metabolism. Roles in tumor progression and survival. Cancer Metastasis Rev. 26, 503-524.

3. Yoshida, H., and Kisugi, R. (2010) Mechanisms of LDL oxidation. Clin. Chim. Acta 411, 1875-1882

4. Duroudier, N. P., Tulah, A. S., and Sayers, I. (2009) Leukotriene pathway genetics and pharmacogenetics in allergy. Allergy 64, 823-839

5. Ivanov, I., Heydeck, D., Hofheinz, K., Roffeis, J., O’Donnell, V. B., Kuhn, H., and Walther, M. (2010) Molecular enzymology of lipoxygenases. Arch. Biochem. Biophys. 503, 161-174

6. Schneider, C., Pratt, D. A., Porter, N. A., and Brash, A. R. (2007) Control of oxygenation in lipoxygenase and cyclooxygenase catalysis. Chem. Biol. 14, 473-488

7. Kuhn, H., Saam, J., Eibach, S., Holzhütter, H. G., Ivanov, I., and Walther, M. (2005) Structural biology of mammalian lipoxygenases. Enzymatic consequences of targeted alterations of the protein structure. Biochem. Biophys. Res. Commun. 338, 93-101

8. Sloane, D. L., Leung, R., Craik, C. S., and Sigal, E. (1991) A primary determinant for lipoxygenase positional specificity. Nature 354, 149-152

9. Chen, X. S., and Funk, C. D. (1993) Structure-function properties of human platelet 12-lipoxygenase. Chimeric enzyme and in vitro mutagenesis studies. FASEB J. 7, 694-701

10. Borngräber, S., Kuban, R. J., Anton, M., and Kühn, H. (1996) Phenylalanine 353 is a primary determinant for the positional specificity of mammalian 15-lipoxygenases. J. Mol. Biol. 264, 1145-1153

11. Borngräber, S., Browner, M., Gillmor, S., Gerth, C., Anton, M., Fletterick,
R., and Kühn, H. (1999) Shape and specificity in mammalian 15-lipoxygenase active site. The functional interplay of sequence determinants for the reaction specificity. J. Biol. Chem. 274, 37345-37350

12. Vogel, R., Jansen, C., Roffeis, J., Reddanna, P., Forsell, P., Claesson, H. E., Kuhn, H., and Walther, M. (2010) Applicability of the triad concept for the positional specificity of mammalian lipoxygenases. J. Biol. Chem. 285, $5369-5376$

13. Gan, Q. F., Browner, M. F., Sloane, D. L., and Sigal, E. (1996) Defining the arachidonic acid binding site of human 15-lipoxygenase. Molecular modeling and mutagenesis. J. Biol. Chem. 271, 25412-25418

14. Toledo, L., Masgrau, L., Maréchal, J. D., Lluch, J. M., and González-Lafont, A. (2010) Insights into the mechanism of binding of arachidonic acid to mammalian 15-lipoxygenases. J. Phys. Chem. B 114, 7037-7046

15. Toledo, L., Masgrau, L., Lluch, J. M., and González-Lafont, À. (2011) Substrate binding to mammalian 15-lipoxygenase. J. Comput. Aided Mol. Des. 25, 825-835

16. Boeglin, W. E., Itoh, A., Zheng, Y., Coffa, G., Howe, G. A., and Brash, A. R. (2008) Investigation of substrate binding and product stereochemistry issues in two linoleate 9-lipoxygenases. Lipids 43, 979-987

17. Jisaka, M., Iwanaga, C., Takahashi, N., Goto, T., Kawada, T., Yamamoto, T., Ikeda, I., Nishimura, K., Nagaya, T., Fushiki, T., and Yokota, K. (2005) Double dioxygenation by mouse $8 S$-lipoxygenase. Specific formation of a potent peroxisome proliferator-activated receptor $\alpha$ agonist. Biochem. Biophys. Res. Commun. 338, 136-143

18. Neau, D. B., Gilbert, N. C., Bartlett, S. G., Boeglin, W., Brash, A. R., and Newcomer, M. E. (2009) The 1.85- $\AA$ structure of an $8 R$-lipoxygenase suggests a general model for lipoxygenase product specificity. Biochemistry 48, 7906-7915

19. Gillmor, S. A., Villaseñor, A., Fletterick, R., Sigal, E., and Browner, M. F. (1997) The structure of mammalian 15-lipoxygenase reveals similarity to the lipases and the determinants of substrate specificity. Nat. Struct. Biol. 4, 1003-1009

20. Choi, J., Chon, J. K., Kim, S., and Shin, W. (2008) Conformational flexibility in mammalian 15S-lipoxygenase. Reinterpretation of the crystallographic data. Proteins 70, 1023-1032

21. Oldham, M. L., Brash, A. R., and Newcomer, M. E. (2005) Insights from the $\mathrm{X}$-ray crystal structure of coral $8 R$-lipoxygenase. Calcium activation via a C2-like domain and a structural basis of product chirality. J. Biol. Chem. 280, 39545-39552

22. Gilbert, N. C., Bartlett, S. G., Waight, M. T., Neau, D. B., Boeglin, W. E., Brash, A. R., and Newcomer, M. E. (2011) The structure of human 5-lipoxygenase. Science 331, 217-219

23. Walther, M., Wiesner, R., and Kuhn, H. (2004) Investigations into calcium-dependent membrane association of 15-lipoxygenase-1. Mechanistic roles of surface-exposed hydrophobic amino acids and calcium. J. Biol. Chem. 279, 3717-3725

24. Kulkarni, S., Das, S., Funk, C. D., Murray, D., and Cho, W. (2002) Molecular basis of the specific subcellular localization of the C2-like domain of 5-lipoxygenase. J. Biol. Chem. 277, 13167-13174

25. Mortimer, M., Järving, R., Brash, A. R., Samel, N., and Järving, I. (2006) Identification and characterization of an arachidonate $11 R$-lipoxygenase. Arch. Biochem. Biophys. 445, 147-155

26. Walther, M., Hofheinz, K., Vogel, R., Roffeis, J., and Kühn, H. (2011) The $\mathrm{N}$-terminal $\beta$-barrel domain of mammalian lipoxygenases including mouse 5-lipoxygenase is not essential for catalytic activity and membrane binding but exhibits regulatory functions. Arch. Biochem. Biophys. 516, $1-9$

27. Ivanov, I., Di Venere, A., Horn, T., Scheerer, P., Nicolai, E., Stehling, S., Richter, C., Skrzypczak-Jankun, E., Mei, G., Maccarrone, M., and Kühn, H. (2011) Tight association of N-terminal and catalytic subunits of rabbit 12/15-lipoxygenase is important for protein stability and catalytic activity. Biochim. Biophys. Acta 1811, 1001-1010

28. Allard, J. B., and Brock, T. G. (2005) Structural organization of the regulatory domain of human 5-lipoxygenase. Curr. Protein Pept. Sci. 6, $125-131$

29. Jankun, J., Doerks, T., Aleem, A. M., Lysiak-Szydłowska, W., and Skrzypczak-Jankun, E. (2008) Do human lipoxygenases have a PDZ regulatory domain? Curr. Mol. Med. 8, 768-773 
30. Aleem, A. M., Jankun, J., Dignam, J. D., Walther, M., Kühn, H., Svergun, D. I., and Skrzypczak-Jankun, E. (2008) Human platelet 12-lipoxygenase, new findings about its activity, membrane binding, and low-resolution structure. J. Mol. Biol. 376, 193-209

31. Shang, W., Ivanov, I., Svergun, D. I., Borbulevych, O. Y., Aleem, A. M., Stehling, S., Jankun, J., Kühn, H., and Skrzypczak-Jankun, E. (2011) Probing dimerization and structural flexibility of mammalian lipoxygenases by small-angle x-ray scattering. J. Mol. Biol. 409, 654-668

32. Koljak, R., Boutaud, O., Shieh, B. H., Samel, N., and Brash, A. R. (1997) Identification of a naturally occurring peroxidase-lipoxygenase fusion protein. Science 277, 1994-1996

33. Lõhelaid, H., Järving, R., Valmsen, K., Varvas, K., Kreen, M., Järving, I., and Samel, N. (2008) Identification of a functional allene oxide synthase-lipoxygenase fusion protein in the soft coral Gersemia fruticosa suggests the generality of this pathway in octocorals. Biochim. Biophys. Acta 1780, 315-321

34. Coffa, G., Schneider, C., and Brash, A. R. (2005) A comprehensive model of positional and stereo control in lipoxygenases. Biochem. Biophys. Res. Commun. 338, 87-92

35. Studier, F. W. (2005) Protein production by autoinduction in high density shaking cultures. Protein Expr. Purif. 41, 207-234

36. Winter, G. (2010) Xia2. An expert system for macromolecular crystallography data reduction. J. Appl. Crystallogr. 43, 186-190

37. Keegan, R. M., and Winn, M. D. (2007) Automated search-model discovery and preparation for structure solution by molecular replacement. Acta Crystallogr. D Biol. Crystallogr. 63, 447-457

38. McCoy, A. J., Grosse-Kunstleve, R. W., Adams, P. D., Winn, M. D., Storoni, L. C., and Read, R. J. (2007) Phaser crystallographic software. J. Appl. Crystallogr. 40, 658-674

39. Vagin, A. A., Steiner, R. A., Lebedev, A. A., Potterton, L., McNicholas, S., Long, F., and Murshudov, G. N. (2004) REFMAC5 dictionary. Organization of prior chemical knowledge and guidelines for its use. Acta Crystallogr. D Biol. Crystallogr. 60, 2184-2195

40. Collaborative Computational Project, Number 4 (1994) The CCP4 suite. Programs for protein crystallography. Acta Crystallogr. D Biol. Crystallogr. 50, $760-763$

41. Emsley, P., Lohkamp, B., Scott, W. G., and Cowtan, K. (2010) Features and development of Coot. Acta Crystallogr. D Biol. Crystallogr. 66, 486-501

42. Adams, P. D., Afonine, P. V., Bunkóczi, G., Chen, V. B., Davis, I. W., Echols, N., Headd, J. J., Hung, L. W., Kapral, G. J., Grosse-Kunstleve, R. W., McCoy, A. J., Moriarty, N. W., Oeffner, R., Read, R. J., Richardson, D. C., Richardson, J. S., Terwilliger, T. C., and Zwart, P. H. (2010) PHENIX. A comprehensive Python-based system for macromolecular structure solution. Acta Crystallogr. D Biol. Crystallogr. 66, 213-221

43. Pettersen, E. F., Goddard, T. D., Huang, C. C., Couch, G. S., Greenblatt, D. M., Meng, E. C., and Ferrin, T. E. (2004) UCSF Chimera. A visualization system for exploratory research and analysis. J. Comput. Chem. 25, $1605-1612$

44. Sanner, M. F., Olson, A. J., and Spehner, J. C. (1996) Reduced surface. An efficient way to compute molecular surfaces. Biopolymers 38, 305-320
45. Krissinel, E., and Henrick, K. (2007) Inference of macromolecular assemblies from crystalline state. J. Mol. Biol. 372, 774-797

46. Chenna, R., Sugawara, H., Koike, T., Lopez, R., Gibson, T. J., Higgins, D. G., and Thompson, J. D. (2003) Multiple sequence alignment with the Clustal series of programs. Nucleic Acids Res. 31, 3497-3500

47. Gouet, P., Courcelle, E., Stuart, D. I., and Métoz, F. (1999) ESPript. Analysis of multiple sequence alignments in PostScript. Bioinformatics 15, 305-308

48. Chen, V. B., Arendall, W. B., 3rd, Headd, J. J., Keedy, D. A., Immormino, R. M., Kapral, G. J., Murray, L. W., Richardson, J. S., and Richardson, D. C. (2010) MolProbity. All-atom structure validation for macromolecular crystallography. Acta Crystallogr. D Biol. Crystallogr. 66, 12-21

49. Jisaka, M., Kim, R. B., and Boeglin, W. E. (2000) Identification of amino acid determinants of the positional specificity of mouse $8 S$-lipoxygenase and human 15S-lipoxygenase-2. J. Biol. Chem. 275, 1287-1293

50. Youn, B., Sellhorn, G. E., Mirchel, R. J., Gaffney, B. J., Grimes, H. D., and Kang, C. (2006) Crystal structures of vegetative soybean lipoxygenase VLX-B and VLX-D, and comparisons with seed isoforms LOX-1 and LOX-3. Proteins 65, 1008-1020

51. Minor, W., Steczko, J., Stec, B., Otwinowski, Z., Bolin, J. T., Walter, R., and Axelrod, B. (1996) Crystal structure of soybean lipoxygenase L-1 at 1.4- $\AA$ resolution. Biochemistry 35, 10687-10701

52. Chruszcz, M., Wlodawer, A., and Minor, W. (2008) Determination of protein structures. A series of fortunate events. Biophys. J. 95, 1-9

53. Skrzypczak-Jankun, E., Borbulevych, O. Y., Zavodszky, M. I., Baranski, M. R., Padmanabhan, K., Petricek, V., and Jankun, J. (2006) Effect of crystal freezing and small-molecule binding on internal cavity size in a large protein. X-ray and docking studies of lipoxygenase at ambient and low temperature at 2.0-Å resolution. Acta Crystallogr. D Biol. Crystallogr. 62, $766-775$

54. Naylor, C. E., Jepson, M., Crane, D. T., Titball, R. W., Miller, J., Basak, A. K., and Bolgiano, B. (1999) Characterization of the calcium-binding C-terminal domain of Clostridium perfringens $\alpha$-toxin. J. Mol. Biol. 294, 757-770

55. Hammarberg, T., Provost, P., Persson, B., and Rådmark, O. (2000) The $\mathrm{N}$-terminal domain of 5-lipoxygenase binds calcium and mediates calcium stimulation of enzyme activity. J. Biol. Chem. 275, 38787-38793

56. Esser, J., Rakonjac, M., Hofmann, B., Fischer, L., Provost, P., Schneider, G., Steinhilber, D., Samuelsson, B., and Rådmark, O. (2010) Coactosin-like protein functions as a stabilizing chaperone for 5-lipoxygenase. Role of tryptophan 102. Biochem. J. 425, 265-274

57. Palmieri-Thiers, C., Alberti, J. C., Canaan, S., Brunini, V., Gambotti, C., Tomi, F., Oliw, E. H., Berti, L., and Maury, J. (2011) Identification of putative residues involved in the accessibility of the substrate-binding site of lipoxygenase by site-directed mutagenesis studies. Arch. Biochem. Biophys. 509, 82-89

58. Knapp, M. J., Seebeck, F. P., and Klinman, J. P. (2001) Steric control of oxygenation regiochemistry in soybean lipoxygenase-1. J. Am. Chem. Soc. 123, 2931-2932

59. Knapp, M. J., and Klinman, J. P. (2003) Kinetic studies of oxygen reactivity in soybean lipoxygenase-1. Biochemistry 42, 11466-11475 